\title{
The Evaluation of Chinese LBS Quality Based on An Improved SERVQUAL
}

\author{
Jihui Shi, Zhenhua Yang and Xiaoxia Yang
}

Business School, Huzhou University, Xueshi RD. NO.1, 313000, Huzhou, Zhejiang Province, China

\begin{abstract}
With the rapid penetration of mobile Internet, the use of LBS has gradually become a mainstream in China EBusiness. Considering all factors affecting the quality of LBS, an improved SERVQUAL model and a correspondent LBS quality evaluation index system was set up. After analyzing some Chinese LBS service platforms (WeChat, Sina Weibo, Diangping etc.), we have found that the two traditional dimension, tangibility and assurance, have no significant effects. Except for the other three traditional dimensions, the Personal privacy protection, accurate Positioning and Information Security affected user's evaluation much. That denotes Security and Reliability are other important dimensions to improve the quality of LBS.
\end{abstract}

Keywords: Evaluation system, location based service (LBS), SERVQUAL.

\section{INTRODUCTION}

The development of mobile Internet led to the rise of the location-based service (LBS) with varying business models, and shocked the economics and society in China. The statistic shows that the users of Chinese mobile Internet will rush to 650 million, and the user penetration rate of LBS will rise to $83 \%$ until the end of $2014^{1}$. The LBS means that company can get the location of the requirement by mobile communication device, then can provide a wide variety of business services for users with web page, voice, SMS or APPs etc. Currently, the most typical and common LBS APPs include the WeChat, QQ, Dianping, Sina Weibo, Baidu Map etc., and more and more forms of APPs are deeply involving in the evolution of E-Business. But, as we all know, the Prism scandal shocked the world and waked up all people using smart phone. More users began to concern about the security, reliability and the location tracking of LBS. In recent years, many business services using Sign-in gradually withdraw from E-Commerce in China. How to eliminate negative factors present in LBS, and promote the innovation and transformations to keep or enhance the user stickiness are still major challenges. The most important thing is how to evaluate user's perception of the value of LBS.

To study the evaluation of user perception on Chinese mainstream LBS, we have improved the SERVQUAL model and proposed a new evaluation system of LBS to study the service quality of WeChat, Sina Weibo, Dianping etc., whose LBS services are widely used in China. The results include two parts.

1. The E-SERVQUAL model is unsuitable for evaluating the quality of LBS. The Tangibility and Assurance,

\footnotetext{
${ }^{1}$ China Internet Network Information Center(2014), The $34^{\text {th }}$ statistics report on China's Internet development.
}

which are two important dimensions in E-SERVQUAL model, have no significant impact on user's evaluation. Meanwhile, the sub-dimensions of privacy, time to honor commitments and the positioning efficiency have a significant impact on user's perception on LBS quality.

2. The quality of the mainstream LBS in China still has much potential to improve. The quality scores of some widely used LBS APPs in China are all at a moderate level. Especially, China LBS providers should pay more attention on user privacy protection and take more respect for user, not just concern about monetary interests.

The evaluation index system is applied to help LBS provider for accurately understanding user's loyalty for the service and to take specific measures based on the differences of the index values. By using the system, providers can improve their service quality on the one hand, and also can enhance the utilization efficiency of accumulated data of user.

\section{BACKGROUNDS}

It is becoming an irreversible trend that more and more E-Commerce services were transferring and sharing through the location function of smart phones. The SERVQUAL model proposed by Parasuraman, Zeithaml \& Berry (1998) [1] is hard to evaluate comprehensively and accurately by using such new service model based on location.

Since more and more services are transmitted via the Internet, some scholars have spent lot of time and effort to take continuous improvements on the model, and proposed electronic service quality model to evaluate user's perception of service quality in Internet situations. Parasuraman, Zeithaml \& Malhotra (2005) [2] have proposed a multi-project model, which was called E-RECSQUAL model for measuring the quality of electronic service on the basis of E-SQUAL model and for emphasizing the user perception of the quality of website service. But Liu \& Sun. (2011) [3] considered that the connotation of the E-SQUAL model and E-RECSQUAL model are basically the same. The key factor is that compa- 


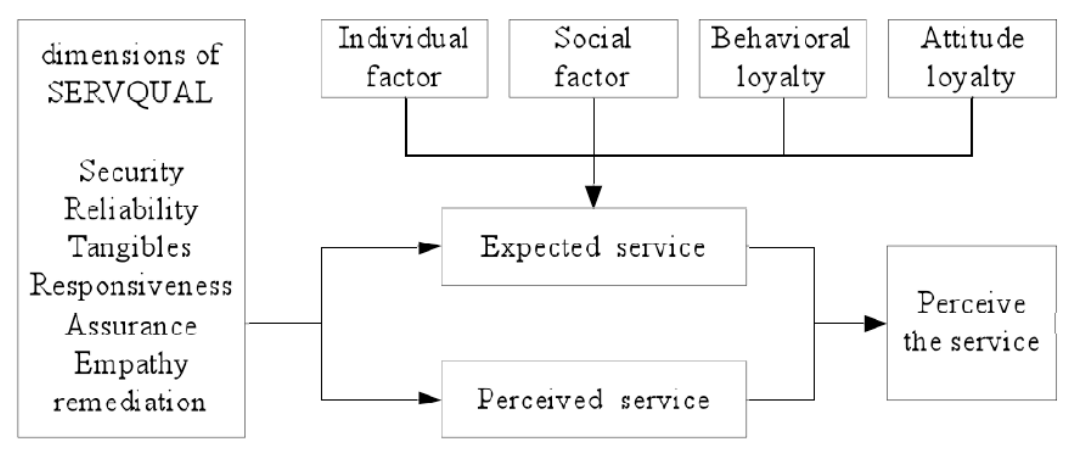

Fig. (1). Theoretical model of LBS SERVQUAL.

nies should take advantage of the consistency of all dimensions to evaluate user's perception with the passage of time and the competition between websites. Christo (2007) [4] argued that the E-SQUAL model is effective and reliable for measuring electronic service, but many studies show that more new electronic services need different dimensions to evaluate. Hans, Tomas \& Maik (2006) [5] designed eTransQual model to study electronic transaction on Internet. The model includes function/design, enjoyment, crafts, reliability and response five dimensions to distinguish. Chinese scholars have contributed much for this study. Zhou \& Lu (2007) [6] have proposed a model of repeat online shopping behavior refereed as the dimension structure of SERVQUAL to survey user's satisfaction. Chang, Liu, Yan \& Zhang (2009) considered that the quality of Internet service should be divided into three parts: service process, quality of service results and quality of service remedy. There are still many other studies about the SERVQUAL, such as SUN et al. (2011), XU et al. (2001) and Shen et al. (2007) [7-9].

The electronic service distributed through mobile Internet depends on the accurate positioning of user requirements. The location factor promotes the realistic feeling of the service, and greatly enhances the immediacy and fragmentation of the service and user behavior. Then, user's perception on the electronic service quality will be more concrete and real. This is quite different with services running via traditional Internet. E-SQUAL and E-RECSQUAL models are difficult to fully reflect this distinction. Some studies addressing this issue to eliminate this dilemma, such as Robert (2004) [10], Beresford \& Stajano (2004) [11], Barkuus \& Anind (2003) [12], Claudio et al. (2005) [13] etc., but the essence to meet user's requirement of information is still the same. The LBS is still one kind of electronic service. So, in order to provide high quality services to meet user's needs, the location data should be used in some reasonable manner. Bharat \& Minakakis (2003) [14] argue that provider's interest demands is the key driving force for getting user location data. So, they have the motivation to provide better location related timely and fascinating information and services by using location data, then to increase provider's financial revenue. For users, these services can offer highly customizable and personalized service to improve their experience and service quality. To achieve the optimal balance between privacy protection and service quality, it's valuable to provide comprehensive and deep assess on the quality of LBS.

\section{AN EXTEND OF SERVQUAL}

\subsection{The Research Model}

According to a lot of previous research and analysis, we took account of the important factors of location based service, such as user's personal privacy information. Based on the five dimensions of the extended SERVQUAL model, we extended the model with two dimensions, security and remediation first. In this research, we have performed correlation test about the seven dimensions after determine the weight, then removing the insignificant part and revising the model again. The model was used to explain the SERVQUAL model as shown in Fig. (1). Then we have used the revised model to study some widely used LBS APPs in China with empirical analysis.

In this paper, Analytic Hierarchy Process (AHP) is adopted, which is classical when making decision. It's a structured technique for organizing and analyzing complex decisions based on mathematics and psychology. The main principle is as follows. First, decompose the decision hierarchically into several easier and more independent subproblems. Second, determine sequence of the relative importance weight of all factors in each layer using questionnaire or expert scoring method. The last, by calculating the relative importance weights of factors in each layer, the composed weight of the bottom layer compared to target layer was conducted. Then using the sequenced weights to analyze or make decision at overall level.

\subsection{Evaluation Index of LBS SERVQUAL}

Based on the research of Parasuraman, Zeithaml \& Malhotra (2005) and Minjeong (2006) [15] etc., we designed the evaluation index system of LBS SERVQUAL according to the characteristics of LBS SERVQUAL. The system contains 3 levels, 7 dimensions and 24 specific sub-indicators as shown in Fig. (2).

\subsubsection{Security}

1). Security mechanism of service: all kinds of LBS provider should establish the sound security mechanisms to improve the user's trust;

2). Safe service process: When to use location-based products and services, it should ensure the safety of the user's process with no other factors to interfere; 


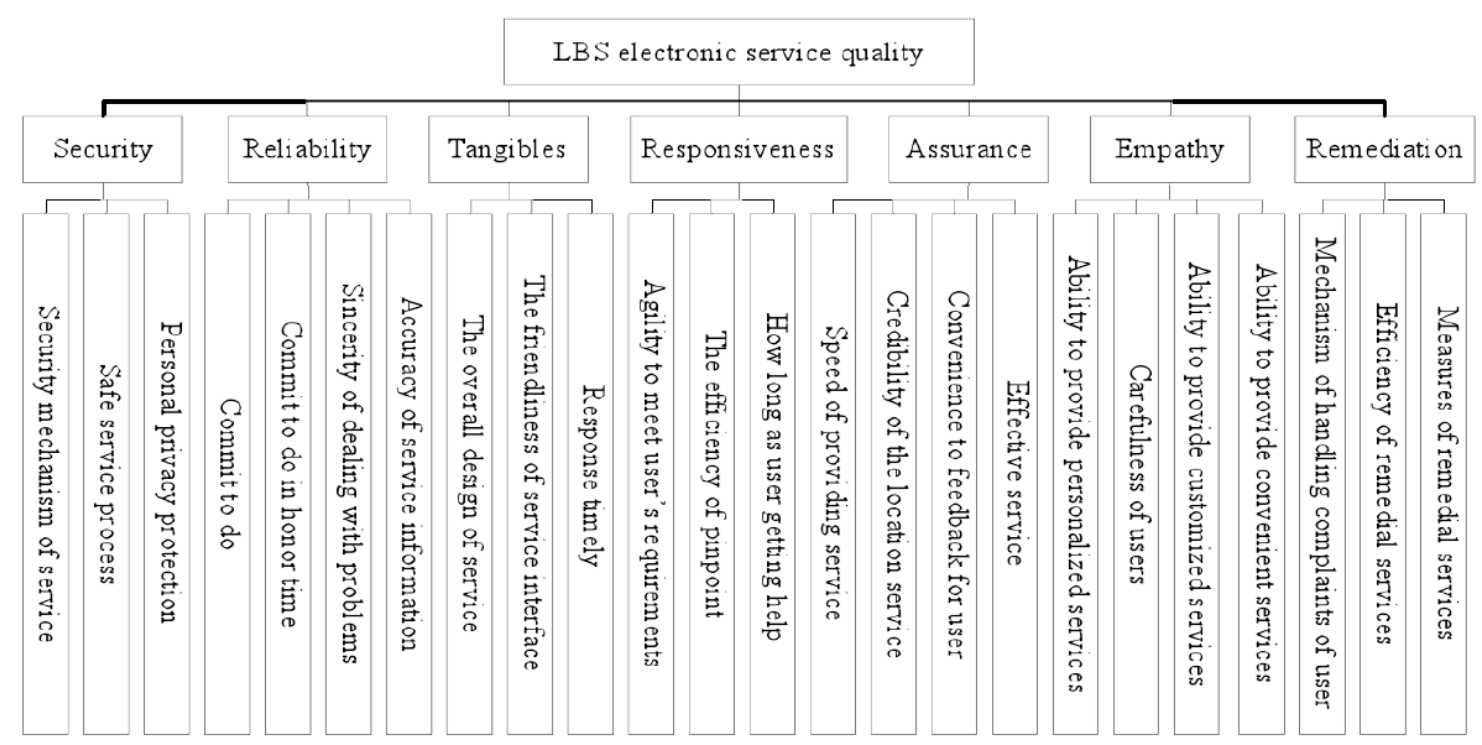

Fig. (2). Hierarchy chart of LBS electronic service quality evaluation.

3). Personal privacy protection: to respect the user and take user as the core, it is necessary to ensure the safety of user information when using location-based products and services.

\subsubsection{Reliability}

1). Commit to do: make the location-based products and services to be consistent in the commitment on advertising;

2). Commit to do in honor time: react promptly when receiving the LBS request from users;

3). Sincerity of dealing with problems: the sincere service attitude is the basis of the user to select the LBS;

4). Accuracy of service information: to provide accurate and effective service information, and only the real information could obtain the user's trust and recognition.

\subsubsection{Tangibility}

1). The overall design of service: it is vital to design all kinds of location-based products and services to meet the needs of users and full of attraction;

2 ). The friendliness of service interface: make service interface to be compatible with the user's mobile devices;

3). Response timely: Users can use all kinds of locationbased products and services quickly.

\subsubsection{Responsiveness}

1). Agility to meet user's requirements: LBS can deal with the request from the user with agility, such as searching for the person nearby;

2). The efficiency of pinpoint: it is vital for user to select the LBS with high efficiency in pinpoint to improve the satisfaction of user;

3). How long as user getting help: handle the needs of LBS for user in a short time and with high efficiency.

\subsubsection{Assurance}

1). Speed of providing service: transmit the input information fast and supply the service timely and accurately as expected;

2). Credibility of the LBS: all kinds of services should supply whole service system to ensure that users are reassured when using it;

3). Convenience to feedback for user: ensure the system with good information feedback mechanism, and to recover the deleted or lost information timely;

4). Effective service: the effective application performance of LBS allows users to keep their faith.

\subsubsection{Empathy}

1). Ability to provide personalized services: make the location-based products and service is personalization;

2). Carefulness of users: take account of users and provide all kinds of services based on the benefit of users.

$3)$. Ability to provide customized services: make the location-based products and services to meet the public demand with strong liquidity;

4). Ability to provide convenient services: No matter what time and where they are, users can easily use the location-based products and services.

\subsubsection{Remediation}

1). Mechanism of handling complaints of user: safeguard the interests of users while enjoying the service;

2). Efficiency of remedial services: to provide relative service timely and make up for the deficiencies of the service when facing problems of the location-based products and services

3). Measures of remedial services: with effective remedial measures to improve the quality of service when problems appearing. 
Table 1. The correlation coefficients between the seven dimensions and the quality of LBS.

\begin{tabular}{|c|c|c|c|c|c|c|c|}
\hline The LBS Quality & Security & Reliability & Tangibility & Responsiveness & Assurance & Empathy & Remediation \\
\hline \hline Pearson Correlation & $.880^{* *}$ & $.313^{* *}$ & .013 & $.327^{* *}$ & .047 & $.411^{* *}$ & $.685^{* *}$ \\
\hline Significance dual & .000 & .000 & .870 & .000 & .548 & .000 & .000 \\
\hline $\mathrm{N}$ & 168 & 168 & 168 & 168 & 168 & 168 \\
\hline
\end{tabular}

**. Correlate at 0.01 level (dual) sig.

Table 2. Judgment matrix of the criterion level.

\begin{tabular}{|c|c|c|c|c|c|}
\hline $\begin{array}{c}\text { LBS Service Quality } \\
\text { Evaluation }\end{array}$ & Security & Reliability & Responsiveness & Empathy & Remediation \\
\hline Security & 1 & $1 / 3$ & $1 / 3$ & 2 & 3 \\
\hline Reliability & 3 & 1 & 1 & 6 & 8 \\
\hline Responsiveness & 3 & 1 & 1 & 6 & 8 \\
\hline Remediation & $1 / 3$ & $1 / 8$ & $1 / 8$ & $1 / 2$ & 1 \\
\hline weight & 0.0720 & 0.1953 & 0.2156 & 0.0395 & 0.0279 \\
\hline
\end{tabular}

Note: $\operatorname{lmax}=7.4513 ; \mathrm{CI}=0.0752 ; \mathrm{RI}=1.36 ; \mathrm{CR}=0.0553$; Consistency test pass.

Table 3. Judgment matrix of security.

\begin{tabular}{|c|c|c|c|}
\hline Security & Security Mechanism of Service & Safe Service Process & Personal Privacy Protection \\
\hline \hline Security mechanism of service & 1 & $1 / 2$ & $1 / 4$ \\
\hline Safe service process & 2 & 1 & $1 / 3$ \\
\hline Personal privacy protection & 4 & 3 & 1 \\
\hline weight & 0.1365 & 0.2385 & 0.6250 \\
\hline
\end{tabular}

Note: $\operatorname{lmax}=3.0184 ; \mathrm{CI}=0.0092 ; \mathrm{RI}=0.52 ; \mathrm{CR}=0.0177$; Consistency test pass.

\subsection{Correlation Analysis}

To test the correlations between the seven characteristic dimensions of the model and the quality of LBS perceived by user, we use SPSS to do Pearson correlation test with Analytic Hierarchy Process with the data collected in the later empirical analysis. Each result is shown in the Table $\mathbf{1}$ below.

Table 1 shows that the Security, Reliability, Responsiveness, Empathy and Remediation have significant correlation with LBS quality at $0.01 \mathrm{sig}$. level. This means there are positive correlations between these five evaluation dimensions and LBS quality, but the Tangibility and Assurance have no significant correlation with LBS quality at $0.01 \mathrm{sig}$. level. The results means that each sub evaluation index of Security, Reliability, Responsiveness, Empathy and Remediation five dimension are main factors of user evaluate the quality of LBS.

\subsection{Determine The Weight With AHP}

The quantitative indicators acquired by questionnaires and the qualitative indicators are mainly obtained through surveys and show user perception. The importance of factors in each level should be judgment. That is to determine the weight of the criterion level to the target level, the relative weight of the index level to the criterion level. Since we build the judgment matrix based on the 1-9 scale by rating from its users. The single weight was obtained through consistency test. As shown in Tables 2-7.

As the weight of Security of LBS, the indicator of Personal Privacy Protection is more important than other indicators as shown in Table 3.

As the weight of reliability of LBS, the indicator of Commit To Do in honor time is more important than the other indicators as shown in Table 4. 
Table 4. Judgment matrix of reliability.

\begin{tabular}{|c|c|c|c|c|}
\hline Reliability & Commit to do & $\begin{array}{c}\text { Commit to do in Honor } \\
\text { Time }\end{array}$ & $\begin{array}{c}\text { Sincerity of Dealing } \\
\text { with Problems }\end{array}$ & $\begin{array}{c}\text { Accuracy of Service } \\
\text { Information }\end{array}$ \\
\hline \hline Commit to do & 1 & $1 / 2$ & 1 & 2 \\
\hline Commit to do in honor time & 2 & 1 & 3 & 4 \\
\hline Sincerity of dealing with problems & 1 & $1 / 3$ & $1 / 2$ & 1 \\
\hline Accuracy of service information & $1 / 2$ & $1 / 4$ & 0.1957 & 0.1083 \\
\hline weight & 0.2166 & 0.4794 & 1 \\
\hline
\end{tabular}

Note: $\operatorname{lmax}=4.0319 ; \mathrm{CI}=0.0106 ; \mathrm{RI}=0.89 ; \mathrm{CR}=0.0119 ;$ Consistency test pass.

Table 5. Judgment matrix of responsiveness.

\begin{tabular}{|c|c|c|c|}
\hline Responsiveness & Agility to Meet User's Requirements & The Efficiency of Pinpoint & How Long as User Getting Help \\
\hline \hline Agility to meet user's requirements & 1 & $1 / 5$ & 2 \\
\hline The efficiency of pinpoint & 5 & 1 & 6 \\
\hline How long as user getting help & $1 / 2$ & $1 / 6$ & 1 \\
\hline weight & 0.1721 & 0.7258 & 0.1020 \\
\hline
\end{tabular}

Note: $\operatorname{lmax}=3.0296 ; \mathrm{CI}=0.0148 ; \mathrm{RI}=0.52 ; \mathrm{CR}=0.0285$; Consistency test pass.

Table 6. Judgment matrix of empathy.

\begin{tabular}{|c|c|c|c|c|}
\hline Empathy & $\begin{array}{c}\text { Ability to Provide } \\
\text { Personalized Services }\end{array}$ & Carefulness of Users & $\begin{array}{c}\text { Ability to Provide } \\
\text { Customized Services }\end{array}$ & $\begin{array}{c}\text { Ability to Provide } \\
\text { Convenient Services }\end{array}$ \\
\hline \hline $\begin{array}{c}\text { Ability to provide } \\
\text { personalized services }\end{array}$ & 1 & $1 / 5$ & 1 & 1 \\
\hline Carefulness of users & 5 & 1 & 1 & 6 \\
\hline $\begin{array}{c}\text { Ability to provide } \\
\text { customized services }\end{array}$ & 1 & $1 / 6$ & 1 & 1 \\
\hline $\begin{array}{c}\text { Ability to provide } \\
\text { convenient services }\end{array}$ & 1 & 0.6530 & 0.1139 & 1 \\
\hline weight & 0.1192 & & 1 & 0.1139 \\
\hline
\end{tabular}

Note: $\operatorname{lmax}=4.0067 ; \mathrm{CI}=0.0022 ; \mathrm{RI}=0.89 ; \mathrm{CR}=0.0025$; Consistency test pass.

Table 7. Judgment matrix of remediation.

\begin{tabular}{|c|c|c|c|}
\hline Remediation & $\begin{array}{c}\text { Mechanism of Handling } \\
\text { Complaints of User }\end{array}$ & Efficiency of Remedial Services & Measures of Remedial Services \\
\hline \hline $\begin{array}{c}\text { Mechanism of handling complaints } \\
\text { of user }\end{array}$ & 1 & 3 & 4 \\
\hline Efficiency of remedial services & $1 / 3$ & 1 & 2 \\
\hline Measures of remedial services & $1 / 4$ & $1 / 2$ & 1 \\
\hline weight & 0.6250 & 0.2385 & 0.1365 \\
\hline
\end{tabular}

Note: $\operatorname{lmax}=3.0184 ; \mathrm{CI}=0.0092 ; \mathrm{RI}=0.52 ; \mathrm{CR}=0.0177$; Consistency test pass.

As the weight of responsiveness of LBS, the indicator of Efficiency of Pinpoint is more important than the other indicators as shown in Table $\mathbf{5}$.

As the weight of empathy of LBS, the indicator of Carefulness of Users is more important than the other indicators as shown in Table 6.
As the weight of remediation of LBS, the indicator of Mechanism of Handling Complaints of User is more important than other indicators as shown in Table 7.

Generally speaking, the user evaluation index of LBS focus much on seven indicators, including personal privacy protection, commit to do in honor time, response timely, the 
Table 8. Assessed value of the LBS evaluation.

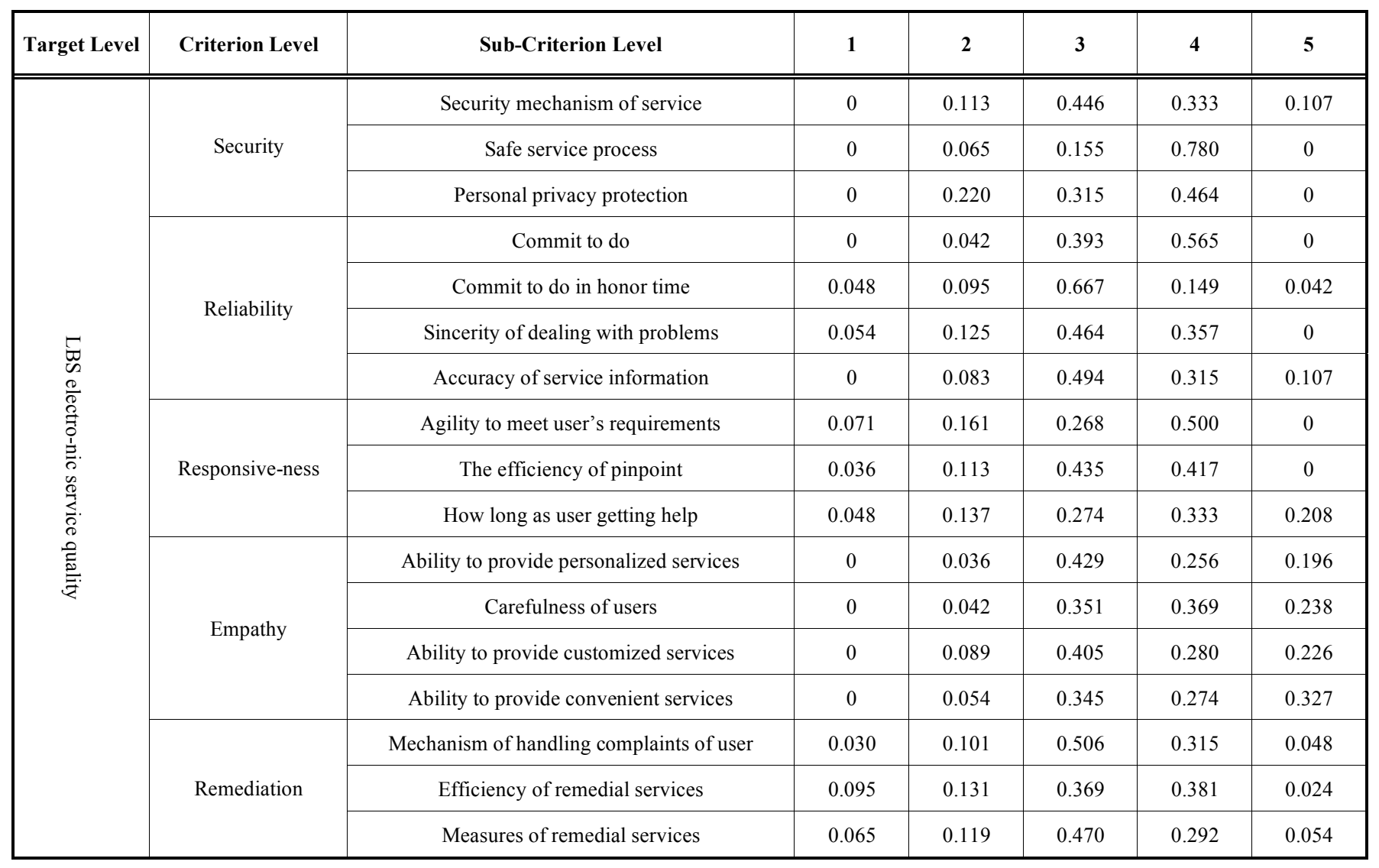

efficiency of pinpoint, effective service, carefulness of users and mechanism of handling complaints of user and so on.

\section{EMPIRICAL ANALYSIS}

This study developed a questionnaire according to the above index system and conducted surveys and research on the user's evaluation of the LBS provided by WeChat, Sina Weibo and Dianping. The below part is an empirical analysis about the LBS application in WeChat, which is the most widely used representative and typical LBS APP in China. For ease to calculation, we have used fuzzy analysis method to quantify the qualitative indicators and compare evaluation factors in the index system, and then have obtained the optimal evaluation value with the maximum membership principle.

\subsection{The Questionnaire And Descriptive Statistics}

According to the LBS quality evaluation index above, we conducted a survey about the LBS (such as: Looking for friends nearby and Shaking service) quality of WeChat perceived by user. By using questionnaire website, E-mail and street survey, 362 samples were recovered and 336 were valid. Users' personal information shows that the proportion of 18-35 years old accounted $97.6 \%$ of the total, the college educations account for $91.27 \%$, university students, white collar and civil services account for $87.6 \%$. These feature of the statistic shows that the age, education level and career distribution of the sample are consistent with Statistical re- port of the 34th China Internet development released by CNNIC in July 2014. It means this survey is effective. The education structure of the sample implies that the respondents can correctly understand the meaning of each index in the questionnaire.

\subsection{Fuzzy Evaluation}

In this section, the main task is to score directly in the five options from 1 to 5 by users. The result of each subindicator is normalized as shown in Table 8.

According to the evaluation index system above, the value (R1, R2, R3, R4, R5) of each index in WeChat LBS is multiplied by the weight (A1, A2, A3, A4, A5). The AHP would get the value of first level in fuzzy evaluation, as shown in Table 9.

Then we calculate the value of sub-level in fuzzy evaluation based on Table 9 as the follows.

\begin{tabular}{|c|c|c|c|c|}
\hline $\mathbf{B}=\mathbf{A} * \mathbf{R}=$ & $(0.0$ & 20 & 1953 & \multirow{2}{*}{$\begin{array}{r}0.2150 \\
0.015\end{array}$} \\
\hline$(0.000$ & 0.168 & 0.295 & 0.521 & \\
\hline 0.034 & 0.088 & 0.549 & 0.298 & 0.032 \\
\hline 0.043 & 0.124 & 0.390 & 0.423 & 0.021 \\
\hline 0.000 & 0.048 & 0.366 & 0.335 & 0.021 \\
\hline 0.050 & 0.111 & 0.468 & 0.328 & 0.043 \\
\hline
\end{tabular}


Table 9. Assessed value in first level of fuzzy evaluation.

\begin{tabular}{|c|c|}
\hline Index & Assessed Value in First Level of Fuzzy Evaluation \\
\hline \hline Security (B1) & $(0.0000 .1680 .2950 .5210 .015)$ \\
\hline Reliability (B2) & $(0.0340 .0880 .5490 .2980 .032)$ \\
\hline Responsiveness (B3) & $(0.0430 .1240 .3900 .4230 .021)$ \\
\hline Empathy (B4) & $(0.0000 .0480 .3660 .3350 .242)$ \\
\hline Remediation (B5) & $(0.0500 .1110 .4680 .3280 .043)$ \\
\hline
\end{tabular}

According to the principle of maximum degree of membership, the overall service quality score of WeChat's LBS is 0.422 based on the above results. It can be assessed that the quality of location-based products and services is still in the moderate level at present.

In the same way, the quality score of Weibo and Dianping are 0.401 and 0.453 . That means, there is still much to improve on the quality of mainstream LBS in China. From results obtained in this research, it is important to improve the personal privacy protection, commit to do in honor time, response timely, provide efficiency of pinpoint, effective service, carefulness of users and mechanism of handling complaints of user and so on to improve the loyalty of users.

\section{CONCLUSION AND RECOMMENDATIONS}

In this paper, we have used an improved SERVQUAL model to evaluate the quality of LBS in China, a widely used services distributed via mobile Internet. According to this model, a LBS assessing index system was developed, then it was used to conduct empirical analysis for the quality of some LBS APPS, such as WeChat, Weibo and Dianping, some widely used and typical LBS APP in China. The result of this study is summarized in two parts.

1. The difference with the existing research is that the Tangibility and Assurance dimensions of SERVQUAL model have no significant impact on user's evaluation of LBS. LBS users take more attention on personal privacy protection, time to honor commitments and positioning efficiency etc. These sub-dimensions have distinguished impact to user's perception of the quality of LBS. The results further denotes that when accessing LBS, user's loyalty and trust were mainly generated from the overall perception of security and reliability of LBS application. There are two possible reasons. The first is that users are more concern about the practicability and timeliness of the service, not the interface design and the accessibility of the service. The second is that the samples and the research method have some defects. Since LBS is still evolving, user still have a high degree of vigilance on personal privacy protection and the reliability of service. This affects the level of user's reception. Meanwhile, different people may have different cognitive level on the model index. The accuracy of values and weights of some index were limited and influenced by subjective factors and user's experience.

2. Though the LBS APPs are booming in China, the service quality are still in a worrying state. The quality scores of WeChat, Weibo and Dianping are all at a moderate level. For the positive results, Chinese LBS providers should improve the service management system further, and pay more attention on user privacy protection first. The next, the reliability of accurate positioning should be promoted more. Once again, to increase the satisfaction of users, the LBS platform should be sounded and optimized based on the characteristic of position. The last one, as a basic functional service in mobile Internet era, providers should learn more from the history of the early LBS websites which use the Sign-in mode to increase user stickiness, and redesign the service, including the service process and privacy protection mechanism. Integrate LBS subtly into some application, not exist independently. That means, only deep integration with other application can totally release the business value of LBS.

\section{CONFLICT OF INTEREST}

The authors confirm that this article content has no conflict of interest.

\section{ACKNOWLEDGEMENTS}

This work was supported by the [Social Science Foundation of Ministry of Education of China] under Grant [14YJC630109].

\section{REFERENCES}

[1] A. Parasuraman, V. A. Zeithaml, and L. L. Berry, "SERVQUAL: A Multi-Item Scale of Measuring Consumer Perceptions of Service Quality," Journal of Retailing, vol. 64, pp. 12-41, 1998.

[2] A. Parasuraman, V. A. Zeithaml, and A. Malhotra, "E-S-QUAL: A Multiple-Item Scale for Assessing Electronic Service Quality," Journal of Service Research, vol. 3, 2005.

[3] L. Liu, and K. Sun, "The influence of electronic service quality and flow on users acceptance of hedonic information system, Systems Engineering-Theory \& Practice, vol. 2, 2011.

[4] B. Christo, "A Psychometric Assessment of E-S-QUAL: A Scale to Measure Electronic Service Quality," Journal of Electronic Commerce Research, vol. 8, pp. 1, 2007.

[5] T. Zhou, and Y. Lu, "Research on Online Consumer Repeat Purchase Behavior Based on SERVQUAL, Journal of management sciences, vol. 3, 2007.

[6] Y. Chang, Y. Liu, J. Yan, and J. Zhang, "Influence mechanism of web service quality on customer loyalty in B2C environment," Systems Engineering-Theory \& Practice, vol. 6, 2009.

[7] J. Sun, B. Xing, and C. Jia, "Building Index System for Ecommerce Customer Satisfaction Based on AHP Theory ," Information Science, vol. 6, 2011. 
[8] M. Xu, and J. Yu, "Application of SERVQUAL Scale to Measure Service Quality," Industrial Engineering and Management, vol. 6, 2001.

[9] W. Shen, X. Zhang, and L. Xie, "Empirical Research of Measurement and Impact of E-service Quality," Journal of management sciences, vol. 1, 2007.

[10] P. M. Robert, "Privacy Issues in Location-Aware Mobile Devices," In: Proceedings of the 37th Hawaii International Conference on System Sciences, 2004.

[11] A. R. Beresford, and F. Stajano, "Mix Zones: User Privacy in Location-aware Services," Unpublished doctoral dissertation, University of Cambridge, England, 2004.
[12] L. Barkuus, and D. Anind, "Location-Based Services for Mobile Telephony: a study of users' privacy concerns," International Conference on Human-Computer Interaction, Interact, 2003.

[13] B. Claudio, X. S. Wang, and J. Sushil, "Protecting Privacy Against Location-based Personal Identification," In: Proceedings of the $2^{\text {nd }}$ VLDB works hop on Secure Data Management, Vol. 3674, pp. 185199, 2005.

[14] R. Bharat, and L. Minakakis, "Evolution of Mobile Location-based Services, Communications of The ACM, vol. 46, pp. 61-65, 2003.

[15] K. Minjeong, "Online service attributes available on apparel retail websites: an E-S-QUAL approach," Managing Service Quality, vol. 16, no. 1, pp.51-77, 2006.

(C) Shi et al.; Licensee Bentham Open.

This is an open access article licensed under the terms of the (https://creativecommons.org/licenses/by/4.0/legalcode), which permits unrestricted, noncommercial use, distribution and reproduction in any medium, provided the work is properly cited. 